\title{
Early numeracy performance of South African school beginners
}

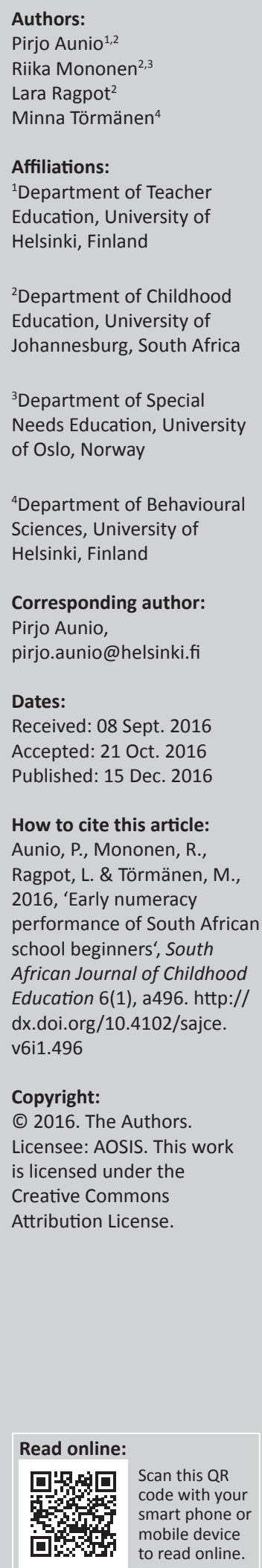

Early numeracy skills are highly relevant for children's mathematics learning at school, especially in the initial years when much mathematics learning relies on early numeracy competence. The aim of this study was to investigate the level of early numeracy skills in a sample of South African children in the first months of formal schooling. In this crosssectional study, there were 443 first graders (206 girls and 237 boys) from Gauteng Province schools. The mean age of the children was 81.61 months (6 years 10 months) (SD 5.40 months). Their early numeracy skills were measured with the ThinkMath Scale. The main finding of this study was that there were statistically significant differences in early numeracy skills between the children when they started first grade. The differences were related to the home language of the first graders in the English medium schools, as well as the type of school (public vs. private). This article concludes that the numeracy competence of the children from the sample was notably varied in the beginning of their formal schooling, which has implications for teaching in the vastly different classroom populations that are all served by one national curriculum.

\section{Introduction}

In the research about innate and core knowledge of numbers (Feigenson, Dehaene \& Spelke 2004) and how core number systems could evolve when learning systematically in a school curriculum, there is consensus that young children have to be offered good possibilities to learn and practice numeracy skills (Dehaene 1997; 2011). Unfortunately, many children, in different parts the world, do not have enough opportunities to learn and practise early numeracy skills in sufficient manner. In South Africa, it is evident from large-scale assessments that children are performing far under the expected grade levels in the first years of primary school (Spaull \& Kotze 2015). Venkat and Spaull (2015) argued that one of the problems in this regard is that teachers' own mathematics knowledge may be one of the reasons why the children do not develop competence. As a consequence, teachers might have problems to know what are the most important maths skills for children to be learnt and how to adapt their teaching to address these. In this study, we set out to explore what kind of early mathematical skills children have when they enter the schools in South Africa.

\section{Early numeracy skills relevant for later mathematics learning}

Knowledge about the development of early numeracy skills and their relevance for later mathematics learning has been increasing rapidly during last 10 years (Aunio \& Räsänen 2015; Fritz, Ehlert \& Balzer 2013; Krajewski \& Schneider 2009). In general, authors agree that numeracy performance in the early childhood years adequately predicts later mathematics performance (Jordan, Glutting \& Ramineni 2010). Especially magnitude comparison, number reading, counting skills, basic arithmetical skills, number line acuity, spontaneous focusing on numerosity and numeracy-related logical knowledge have been found to be relevant for later mathematics performance (Aunio \& Niemivirta 2010; Friso-van den Bos et al. 2015; HannulaSormunen, Lehtinen \& Räsänen 2015; Jordan et al. 2010; Krajewski \& Schneider 2009; LeFevre et al. 2010; Nguyen et al. 2016; Passolunghi, Vercelloni \& Schadee 2007; Toll et al. 2015; Vanbinst, Ghesquière \& De Smedt 2015). Related to the development of mathematical skills in early childhood years, there is an agreement among the researchers that children have biologically primary non-verbal number sense which is the base that children start to learn to use their number word sequence skills first in rhymes and then in enumeration tasks and from that follows the basic strategies for addition and subtraction problem solving (Jordan et al. 2010; Mazzocco, Feigenson \& Halberda 2011). This line of development is further strengthened by learning mathematical relational skills (Aunio \& Niemivirta 2010; Desoete et al. 2009). 
The research results relating to children's development of numerical concepts originate largely from research in the United States, Europe and Asia, and the results from Africa are still scarce (Fritz et al. 2014; Henning 2013, 2014).

\section{Low performance in early numeracy skills}

There are different known causes for early grades children's low performance in mathematics, such as differences in cognitive functions or inadequate opportunities for learning essential mathematical skills (Geary 2013a). A set of longitudinal studies targeting the developmental trajectories of children's numeracy skills revealed that children who enter kindergarten (in this study Grade R) with low performance in numeracy skills remain behind their peers throughout future school years (Aunola et al. 2004; Jordan et al. 2006; Morgan, Farkas \& Wu 2009). Low performance in early numeracy skills learning can be seen, for instance, in poor and slowly developing counting and numerical relational skills (Aunio \& Niemivirta 2010; Desoete et al. 2009). To detect low performance, and hence the risk for later mathematical learning difficulties (MLD), research has applied various cutoff points using percentiles (performance below the 15th, below the 25th or below the 35th percentile) or standard deviations (performance 1 or 1.5 standard deviation below the mean score) in mathematical test performance (Geary 2013b). Especially in early childhood, low performance as a risk factor is more relevant than the diagnosis of MLD, because the criteria for MLD arise from learning difficulties faced by school-aged children (ICD-10: World Health Organization 2016). However, early identification of those children at risk for learning difficulties (i.e. low performance) is crucial as the research has shown that early educational intervention is an effective way to support the learning in the low performance group and potentially preventing later learning difficulties (Wang et al. 2016).

\section{Mathematics performance in South African educational context}

South African school children have demonstrated poor academic outcomes and levels of performance in mathematics (Spaull \& Kotze 2015). The consensus from various studies is that South African learners are performing lower in mathematics when compared with both first world and developing countries, including African and Asian countries (McCarthy \& Oliphant 2013). The findings of a study conducted in 2005 and in 2013 by the Southern and Eastern Africa Consortium for Monitoring Educational Quality (SACMEQ 2014) showed that out of the more than 1000 South African male and female sixth graders who participated in the standardised mathematics test, $80.0 \%$ did not demonstrate an acquisition of the mathematical skills and competencies expected of learners of their age and grade placement (Rademeyer 2014). A more recent national study found that only $58.6 \%$ of the Grade 6 learners who took part in the research were not functionally numerate (Spaull \& Taylor 2012). This overall low performance among older students has highlighted the need for studies in understanding the components which are contributing to the overall low mathematical performance of learners in a South Africa setting such as schools in Gauteng Province. Especially relevant is to understand when the low performance emerges and what components contribute in that.

One of those potential components contributing to the development is the language development (Kleemans, Segers \& Verhoeven 2011; LeFevre et al. 2010; Vukovic \& Lesaux 2013) and language of instruction in the early grades (Taylor \& Van Flintel 2016). In South Africa, schools can form their own language policy, but the national Department of Basic Education (DBE) recommends that children are taught in their home language until Grade 3. There are 11 official languages in the country and the school curriculum provides for content in the different languages. Increasingly, more parents in South Africa select English medium schools for their children because of the social capital they believe it will bring. Henning (2012) explained the conundrum of the 'linguistic maze' created for learning in classrooms where there is rampant code-switching. The reports on literacy learning (National Education Evaluation and Development Unit [NEEDU] 2013, 2014) capture the difficulties encountered in classrooms where the instructional medium is mixed. Gopnik (2001:45) pointed out that recent theories of language and cognition show that 'language restructures cognition (and that) that is congruent with the wider insights of cognitive science'.

In the first grade, the South African curriculum includes numbers, patterns and relationships; patterns, functions and algebra; spaces and shapes; measurement; and data handling (Basic Education Republic of South Africa 2011). Teachers are expected to follow the curriculum chronologically as specified in the curriculum, spending on average 1 hour per day on mathematics teaching, although some schools devise a plan to spend more time on maths. Teachers make use of workbooks, supplied by the public education authorities, to supplement their pedagogy. These workbooks contain multiple examples and suggestions.

Typically, the children in the private schools attend a year of school (kindergarten) before Grade 1, known as Grade R, whereas, in the public schools many children do not attend Grade R. Even though Grade R is the first year of compulsory schooling and forms part of the 4 years which comprise the 'foundation phase' (i.e. elementary school phase), because of affordability of transport and higher school fees (as Grade R is more expensive than day care pre-schools), many parents only place their children in formal schooling in Grade 1. Grade R has been compulsory since 2014, but many parents still adhere to the former notion that Grade 1 as the first year of school. Many parents do not see the benefit of Grade R, which is mostly focused on perceptual, early numeric and literacy development. There are currently many movements in the South African education system to try and change this perception and advocate for the necessity for children to attend Grade R. 


\section{Research questions}

The main aim of this study was to investigate the early numeracy performance of children starting primary school in a sample of South African Gauteng Province schools. We captured the aim into the following research questions:

1. What is the difference between boys and girls in early numeracy performance?

2. What are the differences in performance between the children with different home languages, all of whom learn in an English medium school and were tested in English?

3. What is the difference in performance between children in public and private schools?

4. What are the differences in performance in children between individual schools?

5. How do listening comprehension skills relate to numeracy skills?

6. How are low-performing children distributed according to individual schools and school type?

\section{Research methods and design Participants}

This study is part of the larger research project that investigates the early numeracy learning and evidence-based pedagogical support in South African schools. A total of 443 children (206 girls and 237 boys) participated in this crosssectional study. The mean age of children in this study was 81.62 months (6 years and 10 months) (SD 5.40 months). The study was conducted in schools using English as a means of instruction in the greater Johannesburg area and Western Gauteng (Table 1). The sample is a convenience sample from schools in one large South African Province. The schools included both public and private. Even though the private schools in the sample were middle-income private schools, the access to resources (including competent teachers as human resources and class size) in these schools was better than in the public schools, which, in this sample, included three former 'Model C schools' (previously racially segregated for white learners but currently multiracial), in suburban areas. There were also 'township' (traditionally segregated areas for black children) schools in the sample. The 'township' school uses also English as a teaching language, although it is for many children as second or even a third language.

The private schools in this sample have access to special educational support professionals, occupational therapists and speech therapists, who assist children who had been identified with difficulties in their learning and development. The public schools in this sample were supported by only few professionals in the local school district office, who have to serve more children than they can accommodate properly. Even though schools were supposed to have a school-based learning support team with suitable special education competence, they have difficulties in guaranteeing that all of these professionals have the necessary background to assist children in public schools sufficiently.

The children in this study were starting their primary school in Grade 1 at the time of the study. Children $(N=443)$ came from at least seven home language backgrounds: Setswana $(n=132)$, isiXhosa $(n=14)$, isiZulu $(n=58)$, Sesotho $(n=20)$, English $(n=164)$, Afrikaans $(n=13)$ and some other $(n=42)$. The language of learning and instruction (LoLT) in the sampled schools is English, which is, thus, for the majority of children, a first additional language (FAL) or even a third language.

TABLE 1: Demographic descriptives (age, gender, race, home language and low performance in numeracy skills) by school.

\begin{tabular}{|c|c|c|c|c|c|c|c|}
\hline \multirow[t]{2}{*}{ Variable } & \multicolumn{7}{|c|}{ School } \\
\hline & A & B & C & D & E & $\mathbf{F}$ & G \\
\hline \multicolumn{8}{|l|}{ School } \\
\hline Type & Public & Public & Private & Public & Private & Public & Private \\
\hline Category & Mainstream & Mainstream & Remedial & Mainstream & Mainstream & Mainstream & Mainstream \\
\hline Location & Semi-rural & Urban & Urban & Semi-rural & Urban & Urban & Urban \\
\hline $\begin{array}{l}\text { Socio-economic status (according } \\
\text { to school fees) }\end{array}$ & Middle-low & Middle-low & High & Middle-low & Middle-high & Low & Middle-high \\
\hline$N$ of Grade 1 classes & 2 & 2 & 2 & 3 & 2 & 3 & 3 \\
\hline Class size ( $n$ of children) & $23-25$ & $35-38$ & $7-8$ & $35-40$ & $18-20$ & $35-40$ & $15-18$ \\
\hline$N$ of children & 48 & 76 & 16 & 106 & 38 & 104 & 55 \\
\hline Boys (\%) & $28(41.7)$ & $47(61.8)$ & $8(50.0)$ & $56(52.8)$ & $20(52.6)$ & $46(44.2)$ & $32(58.2)$ \\
\hline Girls (\%) & $20(58.3)$ & $29(38.2)$ & $8(50.0)$ & $50(47.2)$ & $18(47.4)$ & $58(55.8)$ & $23(41.8)$ \\
\hline Mean age in months (SD) & $82.67(4.46)$ & $80.68(5.59)$ & $84.20(7.04)$ & $82.34(4.50)$ & $83.03(4.06)$ & $78.73(5.87)$ & $84.40(4.16)$ \\
\hline \multicolumn{8}{|l|}{ Home language } \\
\hline Afrikaans (\%) & $1(2.1)$ & $4(5.3)$ & - & $1(0.9)$ & $1(2.6)$ & $2(1.9)$ & $4(7.3)$ \\
\hline Setswana (\%) & $25(52.1)$ & $6(7.9)$ & $1(6.3)$ & $79(74.5)$ & $1(2.6)$ & $20(19.2)$ & - \\
\hline isiXhosa (\%) & $1(2.1)$ & $1(1.3)$ & - & $2(1.9)$ & - & $8(7.7)$ & $2(3.6)$ \\
\hline isiZulu (\%) & $1(2.1)$ & $7(9.2)$ & - & $10(9.4)$ & $3(7.9)$ & $35(33.7)$ & $2(3.6)$ \\
\hline Sesotho $(\%)$ & $3(6.3)$ & $3(3.9)$ & - & - & - & $14(13.5)$ & - \\
\hline Other $(\%)$ & - & $5(6.6)$ & $1(6.3)$ & $13(12.3)$ & $3(7.9)$ & $14(13.5)$ & $6(10.9)$ \\
\hline$N$ of low-performing children $(\%) \dagger$ & $9(18.8)$ & $4(5.3)$ & 0 & $25(23.6)$ & $1(2.6)$ & $45(43.3)$ & 0 \\
\hline
\end{tabular}

$\dagger$, Low performance=performance at or under -1 SD of mean score of ThinkMath Scale. 


\section{Measurements}

\section{Numeracy skills}

Numeracy skills were assessed using the ThinkMath Scale (Aunio \& Mononen 2012). Initially, the test was developed in Finland, to identify the lowest performing children in need of evidence-based pedagogical support. The test is a groupbased paper-pencil test, focusing on measuring the core early numeracy skills, based on the model of Aunio and Räsänen (2015). The test includes tasks of mathematical relational skills (comparison concepts with quantities and comparison of numbers), counting skills (number sequences forwards and backwards with missing number, and number wordquantity-number symbol relations) and word problems (verbal addition and subtraction problems), where some examples are given in Box 1. One point was given for a correct answer and zero for wrong answer, thus a total score being 43 .

\section{Number and Quantity Concepts subtest}

As the ThinkMath Scale was used for the first time in the South African context, we wanted to validate it in relation to another test, namely, Number and Quantity Concepts, which is a subtest of the standardised Junior South African Intelligence Scale (JSAIS). The Number and Quantity Concepts subtest of JSAIS was used as it was the only currently available instrument that assesses early numeracy skills. A new MARKO-D (Fritz et al. 2014) was not possible to use as individual testing was not possible. JSAIS's Number and Quantity Concepts Part A consists of 30 questions accompanied by pictures and Part B consists of 15 oral questions, with no pictures, which means the children had to understand the spoken language well enough to recognise the content. The Number and Quantity Concepts subtest assesses a young child's ability for numerical and other mathematical cognitive functioning. The test aims to measure competence in (1) counting; (2) applying basic mathematical processes; (3) evaluating quantity, size, length, and contents; (4) in understanding of relational terms; (5) spatial ordering; and (6) relatively concrete mathematical reasoning ability (Madge 1981). Furthermore, the test focuses on mathematical reasoning and mental arithmetic, and auditory sequential short-term memory, utilising numerical material (Madge 1981).

\section{BOX 1: Item examples of ThinkMath Scale.}

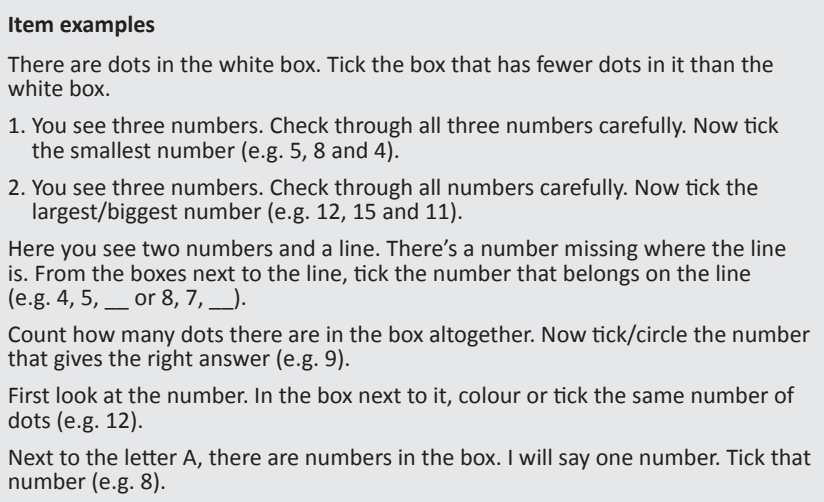

\section{Listening Comprehension Scale}

The children's Listening Comprehension was measured by using a text from a children's story, Gogo's dog (Hartmann \& Rankin 2013), and a Listening Comprehension Scale designed for this study (Ragpot \& Brink 2016), based on the Shell listening comprehension protocol (originally developed by Snow, Burns \& Griffin 1998). The test consists of one story (non-fiction and fiction) with 15 questions.

\section{Procedure}

A native speaker of both Finnish and English translated the ThinkMath Scale in English. The accuracy of translation was checked by the research team. Children's skills were assessed in the beginning of their school year, in March 2016. As the Number Problems was used to validate the ThinkMath Scale, we administered it only with some of the children $(n=180)$, more precisely in schools A, E and F. Trained research assistants and one of the authors administered the tests and scored the papers. Permission to conduct research in the schools was obtained from the Gauteng Department of Education (GDE), the various school management teams, and also the school governing bodies. Then consent letters were sent to families to inform the parents about the research and to obtain their permission that their child could participate.

\section{Results}

\section{Preliminary analyses}

The reliability in terms of Cronbach's alpha for the ThinkMath Scale was high, $\alpha=0.93$ ( $n=443$ children). There were no 'too easy' items (mean $>0.95$ ) and there were neither 'too difficult' items (mean $<0.05$ ). The reliability in terms of Cronbach's alpha for the Number and Quantity Concepts Scale was 0.88 ( $n=180$ children). There were no 'too easy' items (mean $>0$.95) and there were neither 'too difficult' items (mean $<0.05$ ). The Number Problems total score bivariate correlation (Pearson) with ThinkMath total score was $0.671, p<0.01$, indicating that the test-related reliability of ThinkMath Scale in Gauteng Province data was acceptable. The reliability in terms of Cronbach's alpha for the Listening Comprehension Scale was $0.68(n=442$ children). There were no 'too easy' items (mean $>0.95)$ and there were also no 'too difficult' items (mean <0.05).

Parametric tests were used in data analyses as all scales were normally distributed (skewness and kurtosis within -1 - 1).

\section{Main analyses}

Results are reported following the order of the research questions, and means, standard deviations and test values for each analysis are presented in Table 2.

\section{What is the difference between boys and girls in early numeracy performance?}

One-way ANOVA on ThinkMath total score $\times$ gender (two groups) showed that girls and boys were performing equally well, $F(1441)=1.878, p=0.171$. 
TABLE 2: Means, standard deviations and test values in ThinkMath Scale by gender, race, home language, school type and school.

\begin{tabular}{|c|c|c|c|c|c|}
\hline Variable & $N$ & $M(\mathrm{SD})$ & $F(d f 1, d f 2)$ & $p$ & Post-hoc comparison $\dagger$ \\
\hline All & 443 & $27.55(9.50)$ & & & \\
\hline Gender & & & $F(1441)=1.878$ & 0.171 & \\
\hline Boys & 237 & $26.97(10.07)$ & & & \\
\hline Girls & 206 & $28.21(8.77)$ & & & \\
\hline Home language & & & $F(6436)=21.067$ & 0.000 & \\
\hline English & 164 & $32.96(8.27)$ & & & English $>$ Setswana, isizulu, Sesotho and other \\
\hline Afrikaans & 13 & $30.85(9.97)$ & & & Afrikaans $>$ isiZulu \\
\hline Setswana & 132 & $23.60(7.83)$ & & & Setswana $<$ English \\
\hline isiXhosa & 14 & $26.29(10.91)$ & & & \\
\hline isizulu & 58 & $22.40(8.41)$ & & & isiZulu $<$ English and Afrikaans \\
\hline Sesotho & 20 & $23.05(7.77)$ & & & Sesotho $<$ English \\
\hline Other & 42 & $27.52(9.67)$ & & & Other < English \\
\hline School type & & & $F(1441)=172.949$ & 0.000 & \\
\hline Public & 334 & $24.58(8.63)$ & & & \\
\hline School & & & $F(6436)=52.331$ & 0.000 & \\
\hline A & 48 & $24.58(6.68)$ & & & $\mathrm{A}<\mathrm{B}, \mathrm{C}, \mathrm{E}$ and $\mathrm{G}$ \\
\hline B & 76 & $31.17(7.01)$ & & & $\mathrm{B}>\mathrm{A}, \mathrm{D}, \mathrm{E}, \mathrm{F}$ and $\mathrm{G}$ \\
\hline C & 16 & $31.56(6.60)$ & & & $C>A, D$ and $F$ \\
\hline D & 106 & $23.91(7.47)$ & & & $\mathrm{D}<\mathrm{B}, \mathrm{C}, \mathrm{E}, \mathrm{F}$ and $\mathrm{G}$ \\
\hline E & 38 & $35.66(7.01)$ & & & $E>A, B, D$ and $F$ \\
\hline $\mathrm{F}$ & 104 & $20.74(8.89)$ & & & $\mathrm{F}<\mathrm{B}, \mathrm{C}, \mathrm{D}, \mathrm{E}$ and $\mathrm{G}$ \\
\hline G & 55 & $38.25(3.78)$ & & & $G>A, B, C, D$ and $F$ \\
\hline
\end{tabular}

$\dagger$, Post-hoc comparison with Bonferroni correction. Sign > indicated statistically significantly $(p<0.05)$ better performance (i.e. White $>$ Black means that white children performed statistically significantly better compared to black children). Sign < indicates statistically significantly $(p<0.05)$ worse performance between the groups.

\section{What are the differences in early numeracy performance between the children with the different home languages?}

One-way ANOVA on ThinkMath on total score $\times$ home language (seven groups) showed a statistically significant difference between the groups, $F(6436)=21.076 p<0.001$. The post-hoc analysis with Bonferroni correction showed that the English-speaking (as home language) children were performing better than Setswana, isiZulu, Sesotho and other language group children, and children speaking Afrikaans performed better than isiZulu speaking children.

\section{What is the difference in children's early numeracy performance between public and private schools?}

One-way ANOVA on ThinkMath Scale $\times$ school type (two groups) revealed a statistically significant difference between the groups, $F(1,441)=172.949, p<0.001$. The scores of ThinkMath Scale were higher in private schools than in public schools.

\section{What are the differences in children's early numeracy performance between individual schools?}

One-way ANOVA on ThinkMath $\times$ school (seven schools) showed a statistically significant difference between the groups, $F(6436)=52.331, p<0.001$. The post-hoc analysis with Bonferroni correction showed that there were significant differences between the schools in numeracy performance; the mean score difference between the lowest and highest performing school being 17.51 points. The statistically significant differences $(p<0.05)$ between each school are presented in Table 2.

\section{How do listening comprehension skills relate to early numeracy performance?}

Pearson's bivariate correlational analysis revealed that the Listening Comprehension Scale correlated statistically significantly with the ThinkMath Scale, $r=0.550, p<0.01$ indicating that if the children's listening comprehension skills (and understanding of the language of the text that was read to the children) were good at the beginning of their school year in Grade 1, they also performed well on early numeracy tasks.

\section{How are low-performing children distributed and related to schools and school type?}

There were 84 (19\%) low-performing children (performance at or under -1 SD of total mean score of the ThinkMath Scale) in these sampled Gauteng Province schools. The distribution of low-performing children in different schools is presented in Table 1. All, except one, low-performing children were attending public schools. Half of the low-performing children $(n=45)$ came from one school $(F)$. An additional ANOVA test showed that in school $\mathrm{F}$, children were statistically significantly $(p<0.01)$ younger than children in other schools (except for school B), $F(6435)=10.635, p<0.001$.

\section{Discussion}

The aim of this study was to investigate the school beginners' early numeracy knowledge in a small convenience sample of Gauteng Province schools. We were especially interested in the existence of low performance of early numeracy, as it is a risk for later (MLD) (Jordan et al. 2006; Morgan et al. 2009). The preliminary analysis showed the ThinkMath Scale, originally developed in a Finnish context, worked well in 
assessing the early numeracy skills of children in Gauteng Province schools.

The main finding that emerged from this study was that children who enter Gauteng schools' in the first grade have big heterogeneity in their early numeracy knowledge. This is a common finding also in the international context (Aunio \& Niemivirta 2010; Jordan et al. 2006). It has been explained partly because of the age differences children have when they start their schooling, favouring the older children (Jordan et al. 2006) or because of the numeracy-related experiences had in the early childhood years, favouring the middle-income children (Siegler 2009). Furthermore, individual differences in general cognitive skills, such as in working memory, may partly explain the differences in numeracy performance (Passolunghi et al. 2007). There is contradictory evidence about the effect of gender for the early numeracy skills (e.g. Aunio \& Niemivirta 2010; cf. Penner \& Paret 2008). According to this study, South African boys and girls starting school performed equally well.

The fact that most of the children were studying and tested in English that was not their home language can be important explaining factor. Taylor and Von Fintel (2016) reported that children who could learn in their home language (English, Afrikaans or isiXhosa) seemed to perform well in numeracy tasks. Language instruction and use is clearly an important factor for early learning in South African schools that needs to be studied more and especially related to other subjects learning, such as mathematics.

The most striking result was that the low-performing children were almost all attending public schools that are not well-resourced to support the diversity of learners, especially with regard to the availability of professional support at school or from the school district officer. The children in school F, with most low-performing children, were found to be significantly younger than children in other schools, so young age can be one explaining factor (Jordan et al. 2006). The school $\mathrm{F}$ is located in an urban area known for its poverty and migration. There is also much drug abuse, domestic violence, a high report of alcoholism among families and also many single mother families in this area. Schools like school $\mathrm{F}$ need support for their instructional practice; one way could be to provide them with inexpensive and easy-to-use evidence-based pedagogical support materials for working with low-performing learners (Dowker \& Sigley 2010; Mononen \& Aunio 2016). Other forms of support can be beneficial too, for instance, an in-school breakfast programme (Hochfeld et al. 2016). Currently, the school F is in the school-feeding scheme offering lunch for students, but the children do not receive the food early in the day, when they need it most.

\section{Limitations}

This study gave an overview of the early numeracy skills of South African school beginners in the Gauteng Province in South Africa. To get a more clear and a reliable view of the numeracy skills of a larger and more representative sample of South African children, children from other provinces and in schools where the medium of instruction is not English should be included in the future studies. It is therefore important to have the test translated into the other 10 South African languages, or a selection of them, to find out how children perform on their home language. Furthermore, in this study, only numeracy and listening comprehension skills were measured. In order to explain children's level of numeracy performance in more detail, other factors should be included, such as executive functions and family socio-economic status could be included in future studies.

\section{Implications for the future research and practice}

Low performance in early numeracy is an important indicator for later learning difficulties in mathematics. It is possible to support these low-performing learners educationally so that later problems can be avoided. In the South African context we need to develop easy-to-use evidence-based assessment tools for educators to identify the children who have risk for learning difficulties. We also need to develop inexpensive and easy-to-use evidence-based pedagogical support materials for educators to be used with these at risk learners. This call is relevant for international context as well. We also need to support educators so that the knowledge concerning the (MLD), assessment and intervention increases.

\section{Conclusion}

In this study, the early numeracy skills of South African children were assessed. Children's numeracy knowledge varied and differences were found related to home language of the first graders in the English medium schools, school type (public vs. private) and difference between individual schools. Those children who were attending a public school were performing lower than children in private schools. English-speaking children outperformed children who spoke some other language at home, except for Afrikaans. Adequate educational resources and targeted numeracy evidencebased pedagogical support should be aimed for public schools in low socio-economic areas specifically. It is also important to consider teacher development in collaboration with school-based support teams and district officials.

\section{Acknowledgements}

The authors acknowledge the limitations of the JSAIS. Although it is widely used in the South African context as a measurement of cognitive ability, the test was developed in the 1980s, and its content has never been updated. However, it was fast to administer and had scale for early math similar to ThinkMath Scale. Another possibility could have been the MARKO-D, which is an individual test developed from a German instrument standardised and normed for South Africa (Fritz et al. 2014). However in this study, it was not possible to do so long individual testing with children. 


\section{Competing interests}

The authors declare that they have no financial or personal relationships which may have inappropriately influenced them in writing this article.

\section{Authors' contributions}

P.A. is the main person responsible for writing the article and making the analysis. R.M. has contributed to the writing of the article and making the analysis. L.R. has contributed to the writing of the article and was the main person responsible for data collection. M.T. participated in the process of writing.

\section{References}

Aunio, P. \& Mononen, R., 2012, 'ThinkMath-scale', Kindergarten, unpublished.

Aunio, P. \& Niemivirta, M., 2010, 'Predicting children's mathematical performance in grade one by early numeracy', Learning and Individual Differences 20(5), 427-435. http://dx.doi.org/10.1016/j.lindif.2010.06.003

Aunio, P. \& Räsänen, P., 2015, 'Core numerical skills for learning mathematics in children aged five to eight years - A working model for educators', European Early Childhood Education Research Journal. http://dx.doi.org/10.1080/135029 3X.2014.996424

Aunola, K., Leskinen, E., Lerkkanen, M.-K., \& Nurmi, J.-E., 2004, 'Developmental dynamics of math performance from preschool to grade 2', Journal of Educationa Psychology 96(4), 699-713. http://dx.doi.org/10.1037/0022-0663.96.4.699

Basic Education Republic of South Africa, 2011, Curriculum and assessment policy statement, Grades 1-3, mathematics, Department of Basic Education, Republic of South Africa.

Dehaene, S., 1997/2011, Number sense. How the mind creates mathematics, Oxford University Press, New York.

Desoete, A., Stock, P., Schepense, A., Baeyens, D. \& Roeyers, H., 2009, 'Classification seriation, and counting in grades 1,2 , and 3 as two-year longitudinal predictors for low achieving in numerical facility and arithmetical achievement?', Journal of Psychoeducational Assessment 27(3), 252-264. http://dx.doi.org/10.1177/0734 282908330588

Dowker, A. \& Sigley, G., 2010, 'Targeted interventions for children with arithmetical difficulties', Understanding Number Development and Difficulties 7, 65-81. http:// dx.doi.org/10.1348/97818543370009X12583699332492

Feigenson, L., Dehaene, S. \& Spelke, E.S., 2004, 'Core systems of number', Trends in Cognitive Sciences 8, 307-314. http://dx.doi.org/10.1016/j.tics.2004.05.002

Friso-van den Bos, I., Kroesbergen, E.H., Van Kui, J.E.H., Xenidou-Dervou, I., Jonkman L.M., Van der Schoot, M. et al., 2015, 'Longitudinal development of number line estimation and mathematics performance in primary school children', Journal of Experimental Child Psychology 134, 12-29. http://dx.doi.org/10.1016/j.jecp. 2015.02.002

Fritz, A., Balzer, L., Herholdt, R., Ragpot, L. \& Ehlert, A., 2014, 'A mathematics competence test for Grade 1 children migrates from Germany to South Africa', South African Journal of Childhood Education 4(2), 114-133.

Fritz, A., Ehlert, A. \& Balzer, L., 2013, 'Development of mathematical concepts as basis for an elaborated mathematical understanding', South African Journal of Childhood Education 3(1), 38-67. http://dx.doi.org/10.4102/sajce.v3i1.31

Geary, D.C., 2013a, 'Early foundations for mathematics learning and their relations to learning disabilities', Current Directions in Psychological Science 22(1), 23-27. http://dx.doi.org/10.1177/0963721412469398

Geary, D.C., 2013b, 'Learning disabilities in mathematics. Recent advances', in H.L. Swanson, K.R. Harris \& S. Graham (eds.), Handbook of learning disabilities, pp 239-255, Guilford Press, New York.

Gopnik, A., 2001, 'Theories, language, and culture: Whorf without wincing', in M. Bowerman \& S.C. Levinson (eds.), Language acquisition and conceptual development, pp. 45-69, Cambridge University Press, New York.

Hannula-Sormunen, M.M., Lehtinen, E. \& Räsänen, P., 2015, 'Preschool children's spontaneous focusing on numerosity, subitizing, and counting skills as predictors of their mathematical performance seven years later at school', Mathematical Thinking and Learning 17(2-3), 155-177. http://dx.doi.org/10.1080/10986065.2 015.1016814

Hartmann, W. \& Rankin, J., 2013, Sisi goes to school and other stories, Human \& Rousseau, Cape Town.

Henning, E., 2012, 'Learning concepts, language, and literacy in hybrid linguistic codes: The multilingual maze of urban grade 1 classrooms in South Africa', Perspectives in Education 30, 61-77.

Henning, E., 2013, 'Forging a research community of practice to find out how South African children make their world mathematical', South African Journal of Childhood Education 3(2), 141-155. http://dx.doi.org/10.4102/sajce.v3i1.35
Henning, E., 2014, "Teachers" understanding of mathematical cognition in childhood: Towards a shift in pedagogical content knowledge?', Perspectives in Education 31(3), 139-154.

Hochfeld, T., Graham, L., Patel, L., Moodley, J. \& Ross, E., 2016, 'Does school breakfast make a difference? An evaluation of an in-school breakfast programme in South Africa', International Journal of Educational Development 51, 1-9. http://dx.doi. org/10.1016/j.ijedudev.2016.07.005

Jordan, N.C., Glutting, J. \& Ramineni, C., 2010, 'The importance of number sense to mathematics achievement in first and third grades', Learning and Individual Differences 20, 82-88. http://dx.doi.org/10.1016/j.lindif.2009.07.004

Jordan, N.C., Kaplan, D., Oláh, L. \& Locuniak, M.N., 2006, 'Number sense growth in kindergarten: A longitudinal investigation of children at risk for mathematics difficulties', Child Development 77(1), 153-175. http://dx.doi.org/10.1111/ j.1467-8624.2006.00862.x

Kleemans, T., Segers, E. \& Verhoeven, L., 2011, 'Cognitive and linguistic precursors to numeracy in kindergarten: Evidence from first and second language learners' Learning and Individual Differences 21(5), 555-561. http://dx.doi.org/10.1016/ j.lindif.2011.07.008

Krajewski, K. \& Schneider, W., 2009, 'Early development of quantity to number-word linkage as a precursor of mathematical school achievement and mathematica difficulties: Findings from a four-year longitudinal study', Learning and Instruction 19, 513-526. http://dx.doi.org/10.1016/j.learninstruc.2008.10.002

LeFevre, J.-A., Fasr, L., Skwarchuk, S.-L., Smith-Chant, B.L., Bisanz, J., Kamawar, D. et al., 2010, 'Pathways to mathematics: Longitudinal predictors of performance', Child Development 81(6), 1753-1767. http://dx.doi.org/10.1111/j.1467-8624.2010. 01508.x

Madge, E.M. (ed.), 1981, Manual for the Junior South African Individual Scales (JSAIS) - Part 1: Development and standardisation, South African Human Research Council, Pretoria.

Mazzocco, M.M., Feigenson, L. \& Halberda, J., 2011, 'Preschoolers' precision of the approximate number system predicts later school mathematics performance', PLoS One 6(9), e23749. http://dx.doi.org/10.1371/journal.pone.0023749

McCarthy, J., \& Oliphant, R., 2013, Mathematics outcomes in South African schools. What are the facts? What can be done?, The Centre for Development and Enterprise, Johannesburg.

Mononen, R. \& Aunio, P., 2016, 'Math intervention for low-performing first graders', South African Journal of Childhood Education 6(1), 1-9.

Morgan, P.L., Farkas, G. \& Wu, Q., 2009, 'Five-year growth trajectories of kindergarten children with learning difficulties in mathematics', Journal of Learning Disabilities 42, 306-321. http://dx.doi.org/10.1177/0022219408331037

National Education Evaluation and Development Unit (NEEDU), 2013, National report 2012. The state of literacy teaching and learning in the foundation phase, Department of Basic Education, Pretoria.

National Education Evaluation and Development Unit (NEEDU), 2014, Reading study report 2013. The state of reading in grade 5 in selected rural primary schools, Department of Basic Education, Pretoria.

Nguyen T., Watts, T.W., Duncan, G.J., Clements, D.H., Sarama, J.S., Wolfe, C. et al., 2016, "Which preschool mathematics competencies are most predictive of fifth grade achievement?', Early Childhood Research Quarterly 36, 550-560. http:// dx.doi.org/10.1016/j.ecresq.2016.02.003

Passolunghi, M.C., Vercelloni, B. \& Schadee, H., 2007, 'The precursors of mathematics learning: Working memory, phonological ability and numerical competence Cognitive Development 22, 165-184. http://dx.doi.org/10.1016/j.cogdev.2006. 09.001

Penner, A.M. \& Paret, M., 2008, 'Gender differences in mathematics achievement: Exploring the early grades and the extremes', Social Science Research 37(1) 239-253. http://dx.doi.org/10.1016/j.ssresearch.2007.06.012

Rademeyer, J., 2014, Is SA bottom of the class in maths and science? WEF ranking is meaningless, viewed 12 October 2016, from https://africheck.org/reports

Ragpot, L. \& Brink, S., 2016, Grade 1 Listening Comprehension Scale, University of Johannesburg Centre for Childhood Education Practice (CEPR), Johannesburg.

SACMEQ - The Southern and Eastern Africa Consortium for Monitoring Educational Quality: Reading and Math Achievement Levels, 2014, viewed 15 August 2016 from http://www.sacmeq.org/?q=sacmeq-projects/sacmeq-iv/readingmathlevels

Siegler, R., 2009, 'Improving the numerical understanding of children from low income families', Child Development Perspectives 3(2), 118-124. http://dx.doi.org/10.1111/j. 1750-8606.2009.00090.x

Snow, C.E., Burns, M.S., \& Griffin, P., 1998, Preventing reading difficulties in young children, Department of Education, Washington, DC.

Spaull, N. \& Kotze, J., 2015, 'Starting behind and staying behind in South Africa: The case of insurmountable learning deficits in mathematics', International Journal of Educational Development 41, 13-24. http://dx.doi.org/10.1016/j.ijedudev.2015. 01.002

Spaull, N. \& Taylor, S., 2012, Effective enrolment - Creating a composite measure of educational access and educational quality to accurately describe education system performance in sub-Saharan Africa, viewed 26 August 2015, from www. ekon.sun.ac.za/wpapers/2012

Taylor, S. \& von Fintel, M., 2016, 'Estimating the impact language of instruction in South African primary schools: A "fixed effects approach"', Economics of Education Review 50, 75-89. http://dx.doi.org/10.1016/j.econedurev.2016.01.003

Toll, S.W.M., Van Viersen, S., Kroesbergen, E.H. \& Van Luit, J.E.H., 2015, 'The development of (non)-symbolic comparison skills throughout kindergarten and their relations with basic mathematical skills', Learning and Individual Differences 38, 10-17. http://dx.doi.org/10.1016/j.lindif.2014.12.006 
Vanbinst, K., Ghesquière, P. \& De Smedt, B., 2015, 'Does numerical processing uniquely predict first graders' future development of single-digit arithmetic?' uniquely predict first Prades' future development of single-digit arithmetic?' Learning and Individual Differences 37, 153-160. http://dx.doi.org/10.1016/
j.lindif.2014.12.004

Venkat, H. \& Spaull, N., 2015, 'What do we know about primary teachers' mathematical content knowledge in South Africa? An analysis of SACMEQ 2007', International Journal of Educational Development 41, 121-130.

Vukovic, R.K. \& Lesaux, N.K., 2013, 'The language of mathematics: Investigating the ways language counts for children's mathematical development', Journal of
Experimental Child Psychology 115(2), 227-244. http://dx.doi.org/10.1016/ j.jecp.2013.02.002

Wang, A.H., Firmender, J.M., Power, J.R. \& Byrnes, J.P., 2016, 'Understanding the program effectiveness of early mathematics interventions for prekindergarten and kindergarten environments: A meta-analytic review', Early Education and Development 27(5), 692-713. http://dx.doi.org/10.1080/10409289.2016.1116343

World Health Organization, 2016, International statistical classification of diseases and related health problems 10th revision, viewed 26 July 2016, from: http://apps. who.int/classifications/icd10/browse/2016/en 